\title{
ROUTLEDGECURZON
}

\section{RUSSIAN AND EAST EUROPEAN STUDIES}

New in 2004

\section{BASEES/RoutledgeCurzon series on Russian and East European Studies}

Edited by Richard Sakwa, Univeristy of Kent at Canterbury, UK

The primary aim of this series is to publish original, high-quality, research-level work by both new and established scholars, on all aspects of Russian, Soviet, post-Soviet and East European Studies in humanities and social science subjects. Works of synthesis, reference books, and student textbooks will also be considered. Submissions for prospective authors are welcomed, and should be sent in the first instance to the series editor.
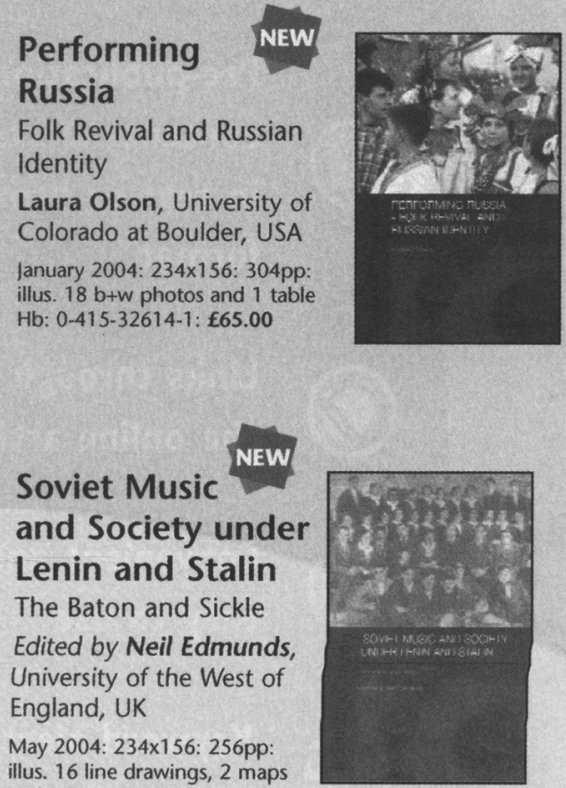
illus. 16 line drawings, 2 maps and $6 \mathrm{~b}+\mathrm{w}$ photos $\mathrm{Hb}: 0-415-30219-6: £ 65.00$

For credit card orders: call $+44(0) 1264343071$ or email book.orders@routledge.co.uk For more information, or for a free Asian Studies catalogue please call $+44(0) 2078422051$ or email julia.davis@tandf.co.uk

\section{RoutledgeCurzon}

Taylor \& Francis Group

\section{Russian Transformations}

Edited by Leo McCann, Cardiff University, UK

This book examines contemporary Russian socioeconomic development, and explores the degree to which Russian experiences can be incorporated into current social science theories.

April 2004: 234x156: 264pp: illus. 6 line drawings and 11 tables

$\mathrm{Hb}: 0-415-32371-1: £ 60.00$

\section{State Building in Ukraine}

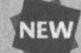
The Ukrainian Parliament, 1990-2003

Sarah Whitmore, Oxford Brookes University, UK

This book examines the development of the Ukrainian parliament - the Verkhovna Rada - from before Ukraine's independence in 1991 to the present.

May 2004: 234x156: 240pp: illus. 6 line drawings and 19 tables

$\mathrm{Hb}: 0-415-33195-1: £ 65.00$

\section{Defending Human Rights in Russia} forthcoming

Sergei Kovalyov, Dissident and Human Rights Commissioner, 1969-2003

Emma Gilligan, University of Chicago, USA This book, by tracing Kovalyov's political career, shows how human rights developed in Russia in late Soviet and post Soviet times.

June 2004: $234 \times 156: 272 \mathrm{pp}$ $\mathrm{Hb}: 0-415-32369-\mathrm{X}: \mathbf{f 6 0 . 0 0}$ 


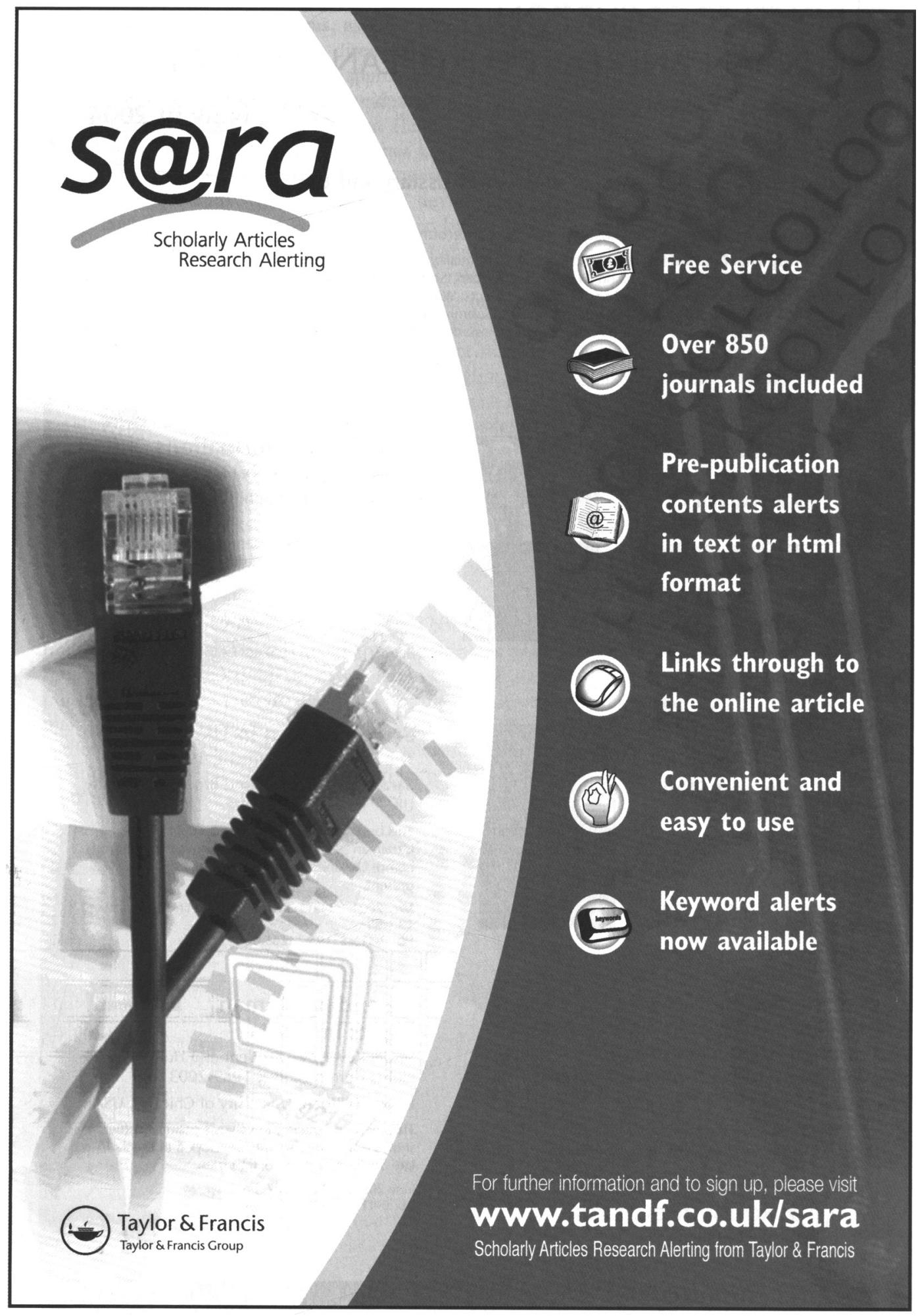




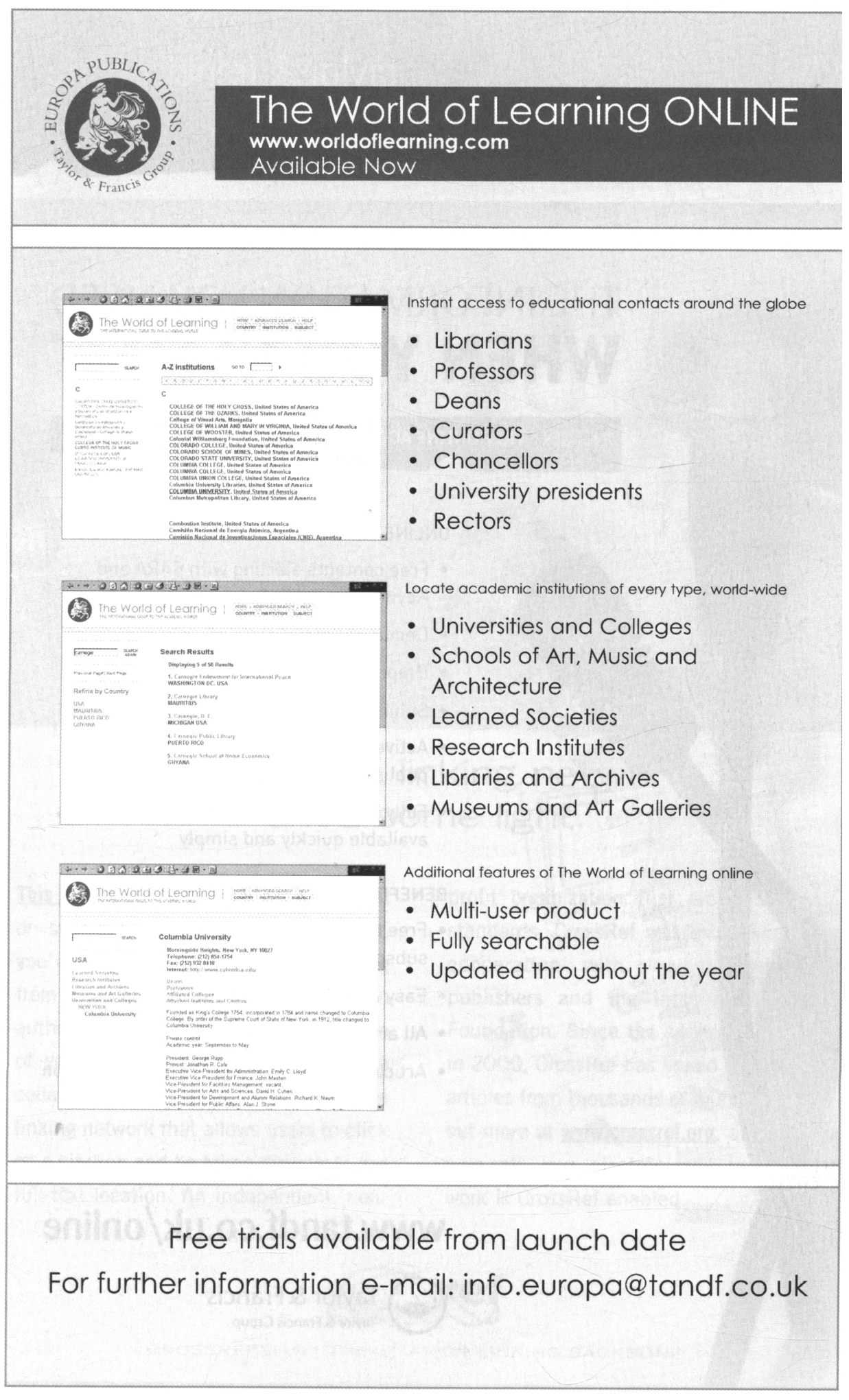




\section{taylor \& francisonline}

\section{THE INFORMATION YOU NEED WHEN YOU NEED IT}

INCLUDES FREE ONLINE ACCESS FOR INSTITUTIONAL SUBSCRIBERS

ONLINE SERVICES FROM TAYLOR \& FRANCIS

- Free contents alerting with SARA and Keyword SARA

- Document delivery for all online journals

- Preprint service from prEview

- Subject arenas

- Active reference linking to over 120 other publishers journals

- Fully searchable electronic sample copies available quickly and simply

\section{BENEFITS}

- Free online access for institutional subscribers

- Easy access to the full text of articles

- All articles fully searchable

- Articles available ahead of print publication

To find out more please visit:

\section{www.tandf.co.uk/online}

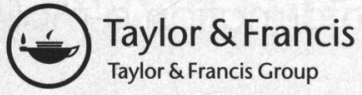




\section{don't publish online in the dark...}

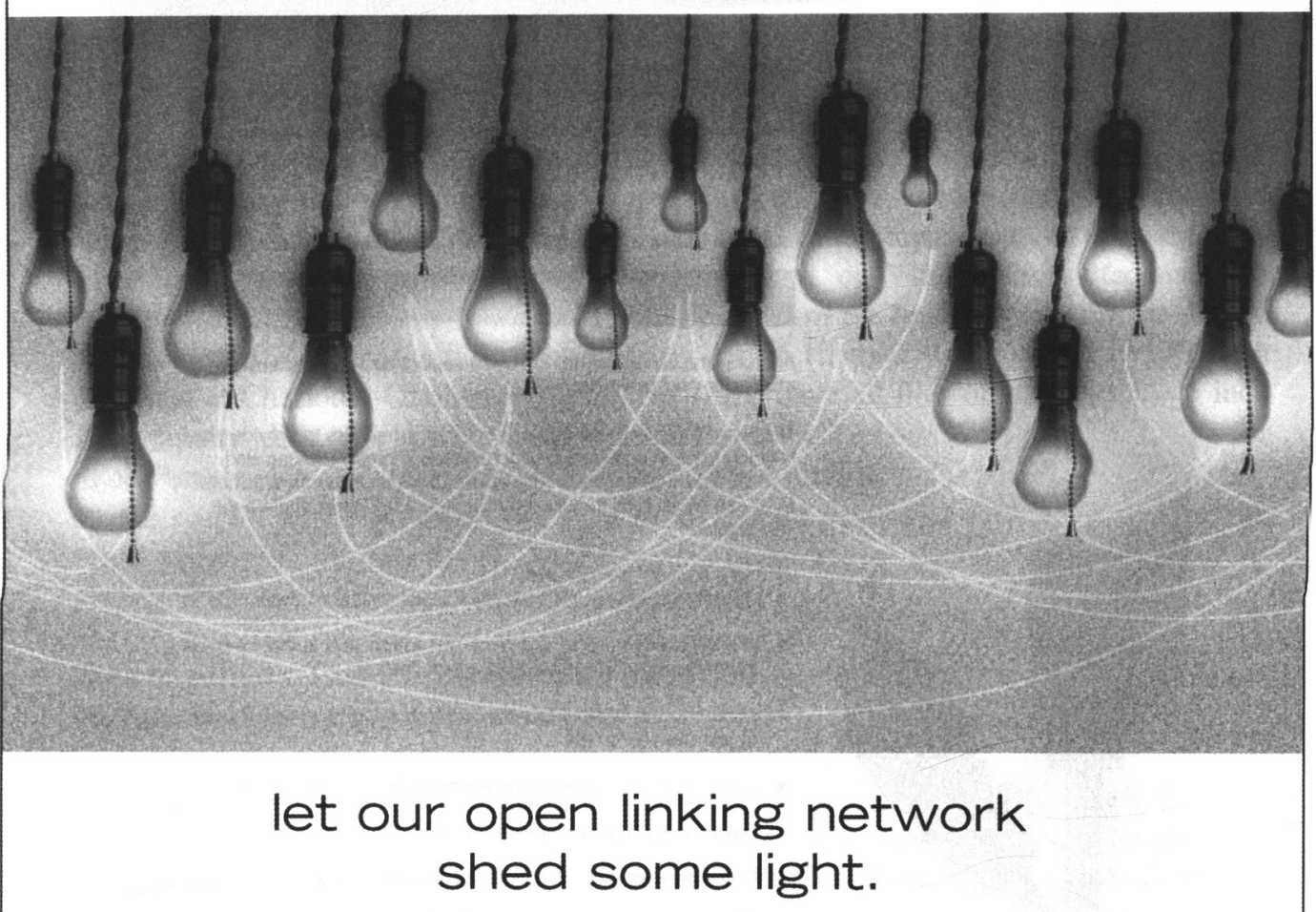

This journal is CrossRef-ed! As a scientist or scholar navigating digital content, you've come to expect dynamic linking from citation to original source. As an author, you expect ready dissemination of your work to others. CrossRef is a collaborative, cross-publisher reference linking network that allows users to click on a citation and be taken directly to the full-text location. An independent, non- profit organization that employs open standards, CrossRef was established in cooperation with leading research publishers and the International DOI Foundation. Since the service went live in 2000, CrossRef has linked millions of articles from thousands of journals. Find out more at www.crossref.org, and make sure all your electronically published work is CrossRef-enabled. 


\section{taylor \& francisonline}

\section{ARENAS FROM TAYLOR \& FRANCIS THE INFORMATION YOU NEED WHEN YOU NEED IT}

www.tandf.co.uk/journals/arenas.html

Arenas are an essential website resource for academics, students and practitioners.

They use the knowledge and expertise of our editors to provide you with information and links to other sites of interest. You can also search across all articles in our online journals programme, submit your site ideas, look for jobs and check out the latest conference information.

Here are some of the features:

- Users are connected to top global research in their field

- The knowledge and expertise of T\&F editors and authors provide information and links to other sites of interest

- Access to the Taylor \& Francis complete catalogue, with listings of journals and books

- Online journals contents pages, abstracts, and full text

- News - including current information on the latest hot topics

- Conference listings - details on all the key international events

- Society links - to major society web pages

Addiction Arena

Anthropology Arena

Arts Arena

Asian Studies Arena

Bioscience Arena

Business \& Management Arena

Development Arena

Economics Arena

Education Arena

Ergonomics Arena

Geography Arena

GIS Arena

Health \& Society Arena

History Arena

Life Sciences Arena

Media \& Cultural Studies Arena

Medicine Arena

PhilosophyArena

Physics \& Chemistry Arena

Politics \& IR Arena

Psychology Arena

Science Arena

Sociology Arena

Sports \& Leisure Studies Arena

Toxicology Arena

\author{
www.addictionarena.com \\ www.anthropologyarena.com \\ www.artsarena.com \\ www.asianstudiesarena.com \\ www.biosciencearena.com \\ www.business.managementarena.com \\ www.developmentarena.com \\ www.economicsarena.com \\ www.educationarena.com \\ www.ergonomicsarena.com \\ www.geographyarena.com \\ www.GISarena.com \\ www.healthandsocietyarena.com \\ www.historyarena.com \\ www.lifesciencesarena.com \\ www.culturalstudiesarena.com \\ www.medicinearena.com \\ www.philosophyArena.com \\ www.physicsarena.com \\ www.politicsarena.com \\ www.psychologyarena.com \\ www.sciencearena.com \\ www.sociologyarena.com \\ www.sports.leisurestudiesarena.com \\ www.toxicologyarena.com
}


NATIONALITIES PAPERS is the only journal in the world which deals exclusively with all nationalities of the former USSR, and also with national minorities in Eastern and Central European countries. The problems and importance of over 140 million people are treated with the disciplinary and methodological contexts of Post-Soviet and Europe-Asia studies. Nationalities Papers is an international and multidisciplinary journal with contributors and readers throughout North America, Western and Eastern Europe, the Far East, Japan and the People's Republic of China. Included in each general issue are in-depth analyses from the historical view, updates on latest developments, some original documents, and book reviews; some issues concentrate on a region or nationality as a special topic, which exclusive focus allows for more extensive and detailed information.

Submission of manuscripts. Authors should send the final, revised version of their articles in both hard copy paper and electronic disk forms. It is essential that the hard copy (paper) version exactly matches the material on disk. Please print out the hard copy from the disk you are sending. Send as a Word or WordPerfect attachment to sosabol@email.uncc.edu or submit two printed copies of the final version with the disk to Steven Sabol, Nationalities Papers, Department of History, The University of North Carolina at Charlotte, Charlotte, NC 28223, USA. Save all files on a standard 3.5 inch high-density disk. We prefer to receive disks in Microsoft Word for Windows or WordPerfect, but can translate from most other common word-processing programs. Please specify which program you have used. Do not save your files as "text only" or "read only". For further details on Electronic Submission, please visit the Taylor \& Francis Website at: http://www.tandf.co.uk/journals

Note to authors. Please make sure your contact address information is clearly visible on the outside of all packages you are sending to Editors.

Copyright. It is a condition of publication that authors vest copyright in their articles, including abstracts, in The Association for the Study of Nationalities. This enables us to ensure full copyright protection and to disseminate the article, and the journal, to the widest possible readership in print and electronic formats as appropriate. Authors may, of course, use the article elsewhere after publication provided that prior permission is obtained from Taylor \& Francis Ltd. Authors are themselves responsible for obtaining permission to reproduce copyright material from other sources. To view the 'Copyright Transfer Frequently Asked Questions' please visit http://www.tandf.co.uk/journals/copyright.asp

\section{THE ASSOCIATION FOR THE STUDY OF NATIONALITIES}

New York

Phone: +12128546239

President Dominique Arel, University of Ottawa, Canada

Vice-Presidents Stefano Bianchini, University of Bologna, Italy

Cynthia Buckley, University of Texas at Austin, USA

Dominique Colas, Institut d'Etudes Politiques de Paris, France

Bhavna Dave, SOAS, UK

Treasurer Gordon Bardos, Harriman Institute, Columbia University, USA

Secretary Catherine Wanner, Penn State University, USA 


\section{Nationalities Papers}

\section{VOLUME 32 NUMBER 3 SEPTEMBER 2004}

\section{ARTICLES}

Local Elections in Indepenent Ukraine: The Case Study of Nikolayev Olena Yatsunska

Fertility, Families and Ethnic Conflict: Macedonians and Albanians in the Republic of Macedonia, 1944-2002

Ulf Brunnbauer

Development and Institutionalisation of Romani Representation and Administration. Part 1

Ilona Klímová-Alexander

Astana's Privatised Independence: Private and National Interests in the Foreign Policy of Nursultan Nazarbayev

Tor Bukkvoll

Christianity and Nationality in Soviet and Post-Soviet Central Asia:

Mutual Intrusions and Instrumentalizations

Sebastien Peyrouse

Evacuation to a Cold Country: Child Refugees from the Greek Civil

War in the German Democratic Republic, 1949-1989

Stefan Troebst 